\title{
Tratamento de esgoto e produção de água de reúso com 0 emprego de filtros de areia
}

\section{Wastewater treatment and reuse water production using sand filters}

\author{
Adriano Luiz Tonetti \\ Engenheiro Químico, Mestre e Doutor em Engenharia Civil (Área de Saneamento e Ambiente) pela Universidade Estadual de Campinas (UNICAMP); \\ Professor Doutor da UNICAMP - Campinas (SP), Brasil. \\ Bruno Coraucci Filho \\ Engenheiro Civil, Mestre e Doutor em Engenharia Civil pela Universidade de São Paulo (USP)- São Paulo (SP), Brasil; Professor Titular da UNICAMP - \\ Campinas (SP), Brasil.

\section{Cintia Elena Nicolau} \\ Tecnóloga em Saneamento pela UNICAMP; Sanitarista Ambiental da Companhia de Saneamento Básico do Estado de São Paulo (SABESP) - \\ Campinas (SP), Brasil. \\ Martina Barbosa \\ Tecnóloga em Saneamento pela UNICAMP; Doutoranda pela UNICAMP - Campinas (SP), Brasil.

\section{Daniele Tonon} \\ Química pela Universidade Estadual Paulista "Júlio de Mesquita Filho" (UNESP) - Araraquara (SP), Brasil; Doutoranda pela UNICAMP - \\ Campinas (SP), Brasil.
}

\section{Resumo}

Nesta pesquisa estudou-se um sistema composto pela combinação de filtro anaeróbio com filtro de areia para o tratamento de esgoto. Para isso, foram avaliados três filtros anaeróbios operados com tempo de detenção hidráulica de nove horas, que tinham o efluente disposto sobre quatro filtros de areia em distintas taxas de aplicações. No primeiro filtro de areia aplicaram-se 50 L.m² uma vez por dia. No segundo, terceiro e quarto filtros, essa mesma carga foi disposta em dois, três e quatro horários, espaçadas entre às 9:00 e às 16:00 horas. O sistema apresentou um efluente final com qualidade que atendia os padrões para reúso e demanda bioquímica de oxigênio abaixo do limite para o lançamento em corpos hídricos (Decreto de Paulista nº 8.468/1976), indicando a viabilidade de disposição de taxas superiores às sugeridas pela NBR 13969/1997, a qual orienta os aspectos construtivos para esta forma de tratamento.

Palavras-chave: esgoto; anaeróbio; filtro de areia; reúso.

\section{Abstract}

In this research it was studied a system composed by the anaerobic filter combined with a sand filter for the wastewater treatment. For this, three anaerobic filters were operated with hydraulic detention time of nine hours which had the effluent disposed over four sand filters in different frequencies of application. On the first sand filter, $50 \mathrm{~L} . \mathrm{m}^{-2}$ were applied once a day. On the second, the third and the fourth filters, the same load was disposed in twice, three and four times a day, distributed between 9 a.m. and 4 p.m. The system presented a final effluent suitable for the COD and BOD legislation maximum limit to be discharged into water body (Decreto Paulista n 8,468/1976), showing the viability of dispose a higher quantity of effluent then the one suggested by NBR 13969/1997, which guides the constructive aspects for this kind of treatment.

Keywords: wastewater; anaerobic; sand filter; reuse. 


\section{Introdução}

A problemática do saneamento básico no Brasil pode ser medida pelo número de municípios existentes no país sem qualquer tipo de serviço de esgotamento sanitário. Segundo o IBGE (2008), 52,2\% das 5.507 cidades brasileiras estavam nesta situação calamitosa. A imensa maioria dos municípios que se encontram em tal conjuntura possui população inferior a 10.000 habitantes e corresponde a 48,4\% de todas as cidades brasileiras, nos quais $47,1 \%$ dos cidadãos vivem na zona rural. Em todo o Brasil, 18,8\% dos habitantes vivem na área rural, tal valor em termos absolutos equivale a mais de 31 milhões de pessoas, número superior a toda a população da região Sul (IBGE, 2008). A maior parte dessas localidades lança seus dejetos in natura nos corpos hídricos ou no solo, comprometendo a qualidade da água utilizada para o abastecimento, irrigação e recreação (TONETTI et al., 2010).

Os processos anaeróbios contribuiriam para a solução desse problema, principalmente aqueles sistemas tidos como simplificados e de baixo custo, tal como o tanque séptico e o filtro anaeróbio. Tendo esse enfoque, a rede temática Programa de Pesquisa em Saneamento Básico (PROSAB) tem realizado muitas pesquisas para o desenvolvimento de métodos de tratamento aplicáveis a esses grupamentos populacionais. Coube à Universidade Estadual de Campinas (UNICAMP) estudar um dos sistemas: foi o tratamento de esgoto doméstico por filtros anaeróbios (COUTO; FIGUEIREDO, 1992; CAMARGO; NOUR, 2001; TONETTI et al., 2011), o qual é uma opção de baixo custo que remove aproximadamente $70 \%$ da matéria orgânica e produz uma quantidade reduzida de lodo. No entanto, como não produzem um efluente adequado aos padrões legais, os sistemas anaeróbios devem ser vistos como uma primeira etapa do processo, necessitando um pós-tratamento que complemente a remoção da matéria orgânica, nutrientes e organismos patogênicos (CHERNICHARO, 2008).

No Brasil, o filtro de areia pode ser utilizado quando se deseja um sistema de pós-tratamento também simplificado. Seu funcionamento baseia-se na aplicação intermitente de afluente sobre a superfície de um leito de areia por meio de uma tubulação de distribuição. Durante a infiltração do líquido incide a purificação por mecanismos físicos, químicos e biológicos (AUSLAND et al., 2002).

A norma brasileira que orienta a construção e operação de filtros de areia — NBR 13969/1997 (ABNT, 1997) — recomenda que no pós-tratamento de efluente do tanque séptico, a taxa de aplicação deve limitar-se a $100 \mathrm{~L} \cdot \mathrm{m}^{-2}$. dia ${ }^{-1}$ e caso seja proveniente de um processo aeróbio, dobra-se esse valor. Onde a temperatura média mensal do esgoto for inferior a $10^{\circ} \mathrm{C}$, os limites serão, respectivamente, de 50 e 100 L.m ${ }^{-2}$.dia ${ }^{-1}$. Apesar de ser uma agência ambiental de um país com clima mais frio, a U.S. Environmental Protection Agency (USEPA) ser uma agência ambiental de um país com clima mais frio, aconselha taxas superiores aos da norma brasileira, variando entre 80 e 200 L.m $^{-2}$. dia-1 quando a alimentação provém do tanque séptico e de 200 a $400 \mathrm{~L} \cdot \mathrm{m}^{-2}$.dia-1 , se originária do filtro aeróbio.

Desse modo, para estudar um sistema simplificado de tratamento de esgotos e contribuir com futuras discussões da NBR 13969/1997, no presente trabalho avaliou-se a associação de filtros anaeróbios com filtros de areia, comparando o efluente gerado com os padrões de lançamento em corpos hídricos (CONAMA, 2005) e para diversas práticas de reúso (OMS, 2000).

\section{Métodos}

Este projeto foi instalado numa área do Laboratório de Protótipos Aplicados ao Tratamento de Águas e Efluentes da Faculdade de Engenharia Civil, Arquitetura e Urbanismo da UNICAMP. O esgoto bruto aplicado nos filtros anaeróbios era proveniente de algumas instalações da universidade, sendo que uma parcela do seu fluxo era bombeada para uma caixa de 1.000 L localizada a 3,20 m de altura, mantida cheia e com constante circulação e transbordamento, visando a manutenção de uma vazão constante no sistema.

A partir dessa caixa, o esgoto era direcionado a três filtros anaeróbios. Cada um deles construído em aço inox com formato cilíndrico e volume total de 500 L. O fundo era cônico e separado da região ocupada pelo meio suporte por uma grade de bambu, funcionando como um compartimento para a distribuição da água residuária (TONETTI et al., 2010). Na Figura 1 está mostrado um esquema e fotos de um destes reatores.

O meio suporte era constituído de anéis de bambu da espécie Bambusa tuldoides, os quais tinham diâmetro de 0,03 m e cortados em tamanho de aproximadamente 0,05 m de comprimento. Após o preenchimento dos reatores com esse material, uma média de $74,7 \pm 0,3 \%$ do volume interno era de vazios e a área superficial chegava a $91,8 \pm 5,4 \mathrm{~m}^{2} \cdot \mathrm{m}^{-3}$. A operação era de fluxo ascendente, com tempo de detenção hidráulica nominal de nove horas, sendo sua vazão controlada duas vezes ao dia.

O líquido que deixava os filtros anaeróbios era direcionado para um recipiente de dosagem que possuía volume total de 60 L e tinha em sua lateral uma graduação correspondente à carga de 50 L.m-2. Da base desse recipiente, partia a tubulação que propiciava a disposição do efluente anaeróbio sobre a superfície de cada um dos quatro filtros de areia. Antes que o líquido encaminhado pela tubulação oriunda do recipiente de dosagem atingisse a superfície dos leitos de areia, havia seu choque com uma placa quadrada de madeira com 0,20 m de comprimento. Na colisão, formavam-se gotículas que eram uniformemente espalhadas sobre o leito.

$\mathrm{Na}$ construção dos filtros de areia foram utilizadas caixas cilíndricas com estrutura de fibra de vidro e diâmetro interno de 1,00 m, abertas na parte superior e com um pequeno orifício de 0,032 m na inferior, onde foi instalada a tubulação de saída do efluente. Para a composição do leito, foram empregadas três camadas estratificadas a partir da base do reator. A primeira possuía $0,20 \mathrm{~m}$ de profundidade e foi composta por Brita 2, com diâmetro efetivo $\left(\mathrm{D}_{10}\right)$ de $16,12 \mathrm{~mm}$, coeficiente de desuniformida-

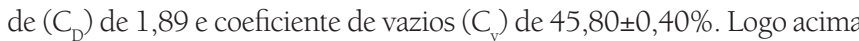
estava a camada formada por Brita 1 com $D_{10}=7,51 \mathrm{~mm}, C_{D}$ de 1,66 e $C_{v}$ de 44,08 $\pm 0,38 \%$, tendo 0,05 $\mathrm{m}$ de profundidade. Esse material objetivava sustentar a areia, impedindo que suas partículas fossem arrastadas para fora da estrutura do sistema. Na Figura 2 está o esquema de um filtro de areia com a disposição das camadas. 
Quanto ao leito de areia adotou-se a profundidade de 0,75 m, que, segundo Tonetti et al. (2010), era o valor mais adequado para o tratamento. A areia empregada foi a popularmente denominada de média, classificada de acordo com procedimento apresentado pela NBR 6502/1995 (ABNT, 1995), a qual possuía um $D_{10}=0,18 \mathrm{~mm}, C_{D}$ de 3,14 e $C_{v}$ de $28,6 \pm 0,9 \%$.

Procurando a ampliação da aeração do leito, foi instalado na lateral de cada filtro um tubo com $0,500 \mathrm{~m}$ de diâmetro interno. No interior do reator, o mesmo penetrava na camada de Brita 2 constituindo uma estrutura com formato de cruz, tendo em toda a sua extensão superior, inferior e laterais perfurações com diâmetro de 0,020 m espaçadas por $0,020 \mathrm{~m}$. A captação do ar era feita de forma natural, não existindo qualquer equipamento mecânico com a finalidade de cumprir tal função.

\section{Aspectos operacionais}

Os filtros anaeróbios foram operados com fluxo ascendente e tempo de detenção hidráulica nominal de nove horas, controlado pela fixação diária de uma vazão de $11,5 \mathrm{~mL} \cdot \mathrm{s}^{-1}$. O líquido proveniente desses reatores foi aplicado entre as segundas-feiras e as sextas-feiras sobre as superfícies dos leitos de areia em cargas de 50 L.m². Para cada um dos filtros de areia este valor foi disposto em uma particular frequência de aplicação e em um curto intervalo de tempo, correspondente ao rápido esvaziamento do recipiente de dosagem. Esta breve disposição buscou simular o uso da válvula ou da caixa de descarga, onde o sistema acabava sendo mais exigido.

No primeiro filtro (FAl), foi empregada a carga de 50 L.m ${ }^{-2}$ uma vez por dia, aplicada às 9:00 horas da manhã. No segundo filtro (FA2), essa carga foi disposta duas vezes ao dia, intervalada pelo prazo de sete horas, ou seja, às 9:00 e às 16:00 horas. No terceiro filtro (FA3), deu-se três vezes ao dia: às 9:00, 12:30 e 16:00 horas. Finalmente no quarto filtro (FA4), as aplicações foram realizadas nos seguintes horários: 9:00, 11:20, 13:40 e 16:00 horas. Na Tabela 1, apresenta-se, de forma esquemática, esse aspecto operacional.

As amostras de esgoto bruto e efluente dos filtros anaeróbios e dos quatro filtros de areia foram coletadas semanalmente, toda terça-feira. A amostragem do esgoto bruto era realizada imediatamente antes de

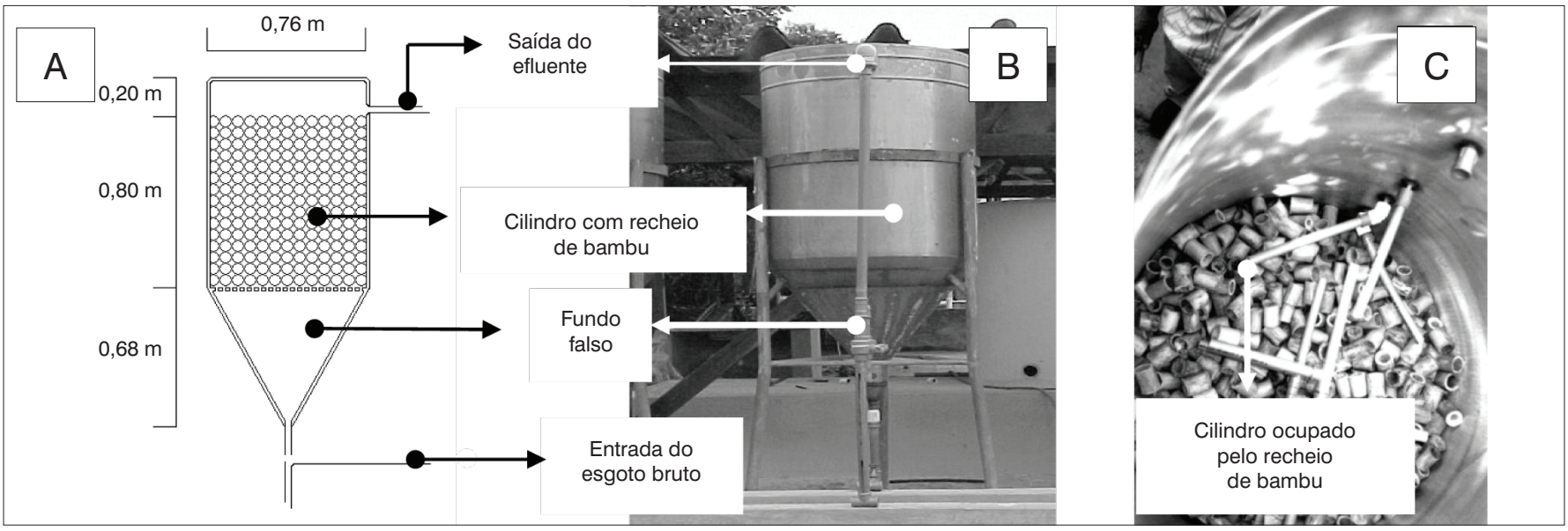

Figura 1 - Esquema de um filtro anaeróbio com recheio de bambu $(A)$ e vistas externa (B) e interna (C).

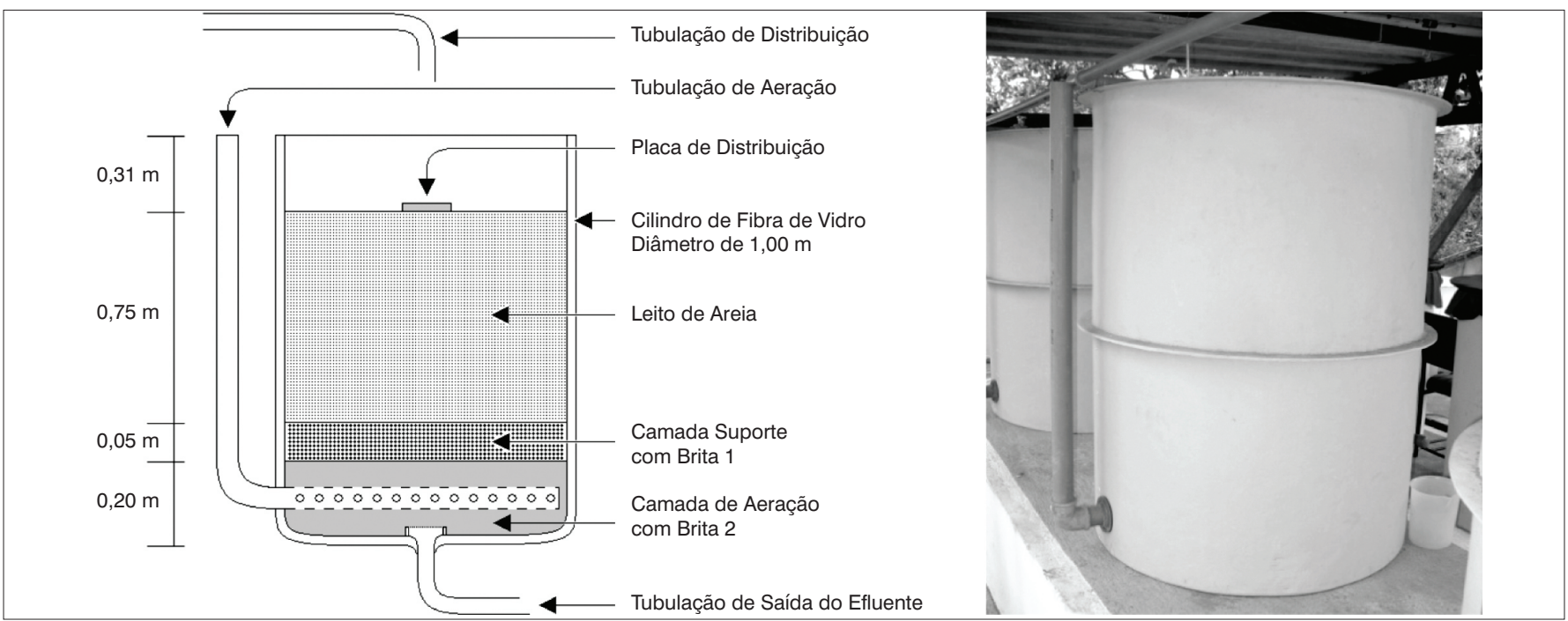

Figura 2 - Esquema e foto dos filtros de areia. 
sua entrada nos filtros anaeróbios enquanto que a coleta unificada do efluente desses reatores dava-se anteriormente a sua aplicação nos leitos de areia. Por sua vez, os efluentes que deixavam os filtros de areia foram coletados na suas tubulações de saída. O início da amostragem dos efluentes dos filtros de areia ocorria após a última disposição diária, quando existia claramente o aumento da vazão de saída do líquido.

As análises das amostras coletadas foram realizadas no Laboratório de Saneamento da Faculdade de Engenharia Civil, Arquitetura e Urbanismo da UNICAMP (LABSAN); todas foram baseadas no Standard Methods for the Examination of Water and Wastewater (APHA; AWWA; WEF, 2005). O período analítico perdurou por 75 semanas, compreendido entre os meses de novembro de 2009 e maio de 2011.

\section{Resultados}

$\mathrm{O}$ esgoto bruto empregado na pesquisa possuía valores de $\mathrm{pH}$ que oscilaram nas proximidades da neutralidade, com média de

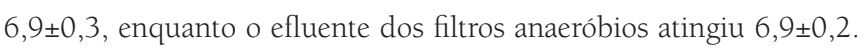
No que tange aos efluentes dos filtros de areia, percebe-se por meio da Figura 3 que após a $9^{a}$ semana da pesquisa deu-se uma grande queda nos $\mathrm{pH}$, chegando a valores inferiores a 5,0 a partir da $13^{\mathrm{a}}$ semana, ou seja, abaixo do limite mínimo estabelecido pela legislação brasileira para o lançamento em corpos hídricos (CONAMA, 2005) e sem diferença significativa (Kruskal-Wallis 5\%) entre os valores dos quatro filtros.

Por meio da Tabela 2, constata-se que o aumento da acidez pode ser explicado pelo processo de nitrificação, que propiciou a geração de efluente com concentração média de $\mathrm{N}-\mathrm{NO}_{2}^{-}+\mathrm{N}-\mathrm{NO}_{3}^{-}$de $26,3 \mathrm{mg} . \mathrm{L}^{-1}$ e de somente $8,6 \mathrm{mg} . \mathrm{L}^{-1}$ para o N-NTK no filtro de areia mais crítico, o qual recebia a maior taxa de aplicação (FA4).
Como consequência da nitrificação teve-se a diminuição dos valores de alcalinidade, notada pela análise da Figura 4.

Até a nona semana, os pH mantinham-se acima de 7,0, com desempenho similar ao obtido por Tonetti et al. (2010) e explicado pela existência de compostos com características básicas na areia que, no decorrer da aplicação diária de afluente, acabavam consumidos ou arrastados para fora do sistema.

Tendo-se em vista adequar o $\mathrm{pH}$ dos efluentes, tanto para o lançamento em um corpo hídrico como para seu emprego na irrigação, decidiu-se adicionar um composto alcalino conjuntamente com a disposição do efluente anaeróbio nos filtros de areia. Para isso, entre a $40^{\mathrm{a}}$ e a $44^{\mathrm{a}}$ semana testou-se o uso de carbonato de cálcio e hidróxido de cálcio, constando-se que ambos formavam um precipitado sobre a superfície do leito, além de não propiciar o desejado aumento dos valores de $\mathrm{pH}$. Desse modo, a partir da $45^{\mathrm{a}}$ semana passou-se a adotar o carbonato de sódio (barrilha), acrescentando $100 \mathrm{~mL}$ de uma solução com concentração de 120 g.L-1 durante todas as disposições de efluente anaeróbio sobre os leitos.

Após o emprego desse composto, ao fazer-se a correlação proposta por Metcalf e Eddy (2003) de que para cada grama de $\mathrm{N}-\mathrm{NH}_{4}^{+}$nitrificado há o dispêndio de 7,07 $\mathrm{g}$ de alcalinidade na forma de $\mathrm{CaCO}_{3}$, a redução nos valores resultante da soma da alcalinidade do efluente anaeróbio e da solução de barrilha equivaleria a oxidação de aproximadamente $52,3 \mathrm{mg} \cdot \mathrm{L}^{-1}$ de nitrogênio amoniacal para nitrato. Tal resultado está muito próximo daquele realmente obtido, visto que em média existiu a nitrificação de $51,8 \mathrm{mg} . \mathrm{L}^{-1}$ do nitrogênio total afluente, não havendo diferença significativa entre os resultados dos filtros de areia em estudo (Kruskal-Wallis 5\%).

Do mesmo modo, ao considerar-se que o efluente dos filtros anaeróbios possuía uma alcalinidade total média de $208 \pm 55 \mathrm{mgCaCO}_{3} \cdot \mathrm{L}^{-1}$, suportaria a nitrificação de apenas 29,4 mg. $\mathrm{L}^{-1}$ de $\mathrm{N}-\mathrm{NH}_{4}^{+}$. Essa concentração de nitrogênio amoniacal está próxima ao extremo inferior dos valores tidos como típicos para águas residuárias de origem doméstica, que

Tabela 1 - Horários e frequência de aplicação de efluente anaeróbio nos filtros de areia.

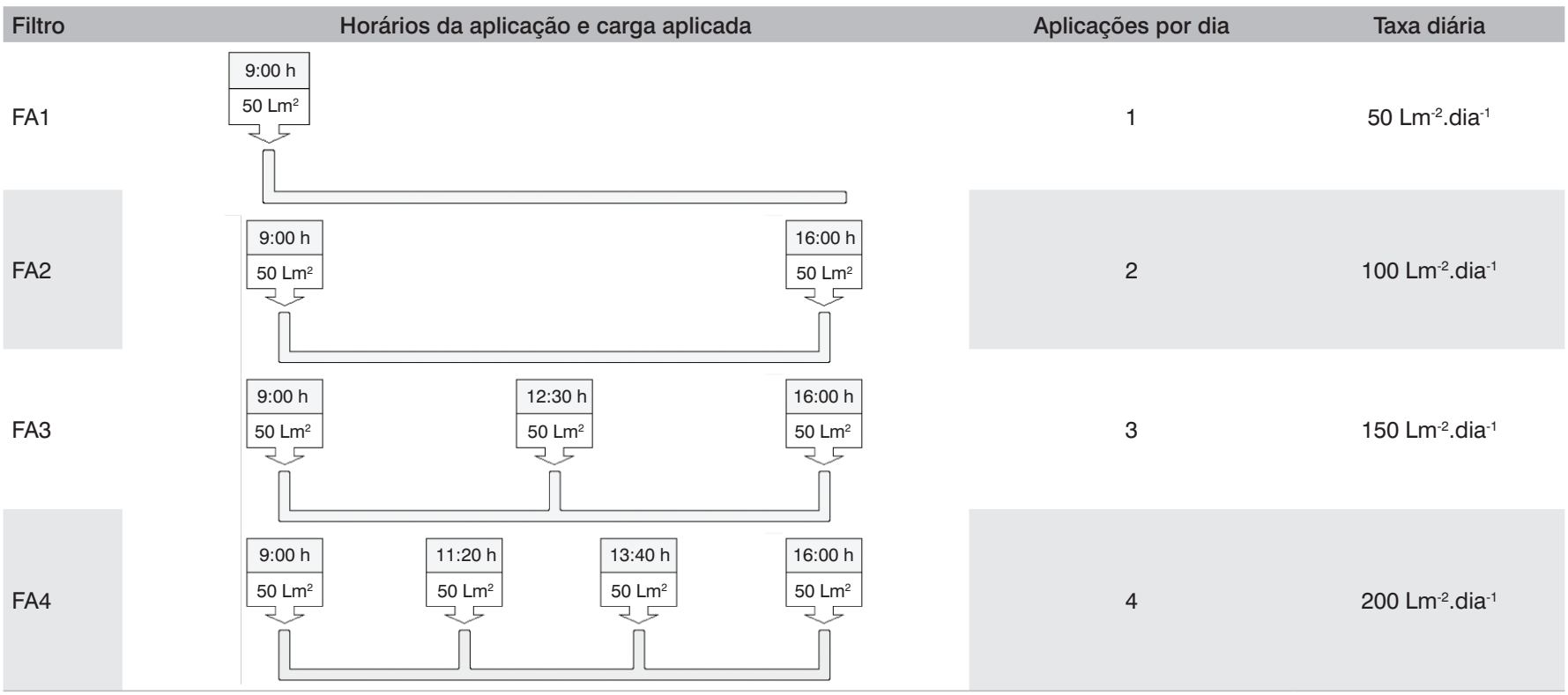

FA1, FA2, FA3 e FA4: filtros 1, 2, 3 e 4, respectivamente. 
oscila entre 35 e $70 \mathrm{mg} . \mathrm{L}^{-1}$ (VON SPERLING, 2009). Porém, o esgoto empregado na pesquisa possuía concentrações superiores a este mínimo e valores de alcalinidade inferiores aos encontrados na literatura, mais precisamente $109 \pm 31 \mathrm{mgCaCO} \cdot \mathrm{L}^{-1}$, correspondendo ao mínimo da faixa estipulada por von Sperling (2009) como típica para este tipo de água residuária, a qual oscila entre 110 e $170 \mathrm{mgCaCO} \mathrm{C}_{3} \cdot \mathrm{L}^{-1}$.

Caso deseje-se a não aplicação de um composto alcalino para a correção do pH, deverá haver uma adequada relação entre o valor de alcalinidade presente no esgoto bruto e, posteriormente no efluente anaeróbio, com a respectiva concentração de nitrogênio total.

\section{Turbidez e sólidos suspensos}

A turbidez média do esgoto bruto foi de 79,8 19,4 UT, enquanto a do efluente dos filtros anaeróbios chegou a 57,9 $9 \pm 24,8$ UT, possibili-

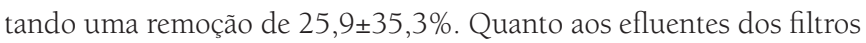
de areia, conforme pode ser visto por meio da Tabela 3, não houve diferença significativa entre os dados encontrados (Kruskal-Wallis 5\%), sendo que todos possuíam valores abaixo do limite máximo para o enquadramento em corpos de água de classe 1 (CONAMA, 2005), que é de 40 UT. Deste modo, garantem-se condições quanto a este parâmetro, para seu emprego na irrigação de hortaliças, plantas frutíferas e de parques, além da aquicultura.
No que se refere aos sólidos suspensos totais, após a passagem pelos filtros anaeróbios, deu-se a remoção média de 39+31\% na sua concentração, chegando a $66 \pm 29 \mathrm{mg} . \mathrm{L}^{-1}$. Quanto aos efluentes dos filtros de areia, pode-se primeiramente visualizar que todos cumpriram a legislação mineira quanto à concentração de sólidos totais em suspensão. Salienta-se que Minas Gerais é o único estado brasileiro que estabelece uma deliberação,COPAM nº 10/1986 (COPAM, 1986), quanto ao lançamento de sólidos suspensos em corpos hídricos, determinando a concentração média mensal de 60 mg...-1 e a máxima diária de 100 mg.L-1.

Tendo-se em vista a possibilidade de reúso, constata-se ao comparar os dados obtidos com os valores propostos por Capra e Scicolone (1998), expostos na Tabela 4, que o efluente teria risco baixo de obstrução dos gotejadores, pois a concentração final era inferior a $50 \mathrm{mg} \cdot \mathrm{L}^{-1}$.

Deve-se ressaltar que apesar de existir uma ação de filtração do leito de areia, ao longo de toda a pesquisa não houve seu entupimento, sendo que esta característica pode estar associada à intermitência da operação que ocasionava a degradação do material depositado superficialmente.

\section{Demanda bioquímica de oxigênio e oxigênio dissolvido}

O valor médio obtido para a demanda bioquímica de oxigênio (DBO) do esgoto bruto foi de $489 \pm 158 \mathrm{mg} . \mathrm{L}^{-1}$, estando dentro da faixa

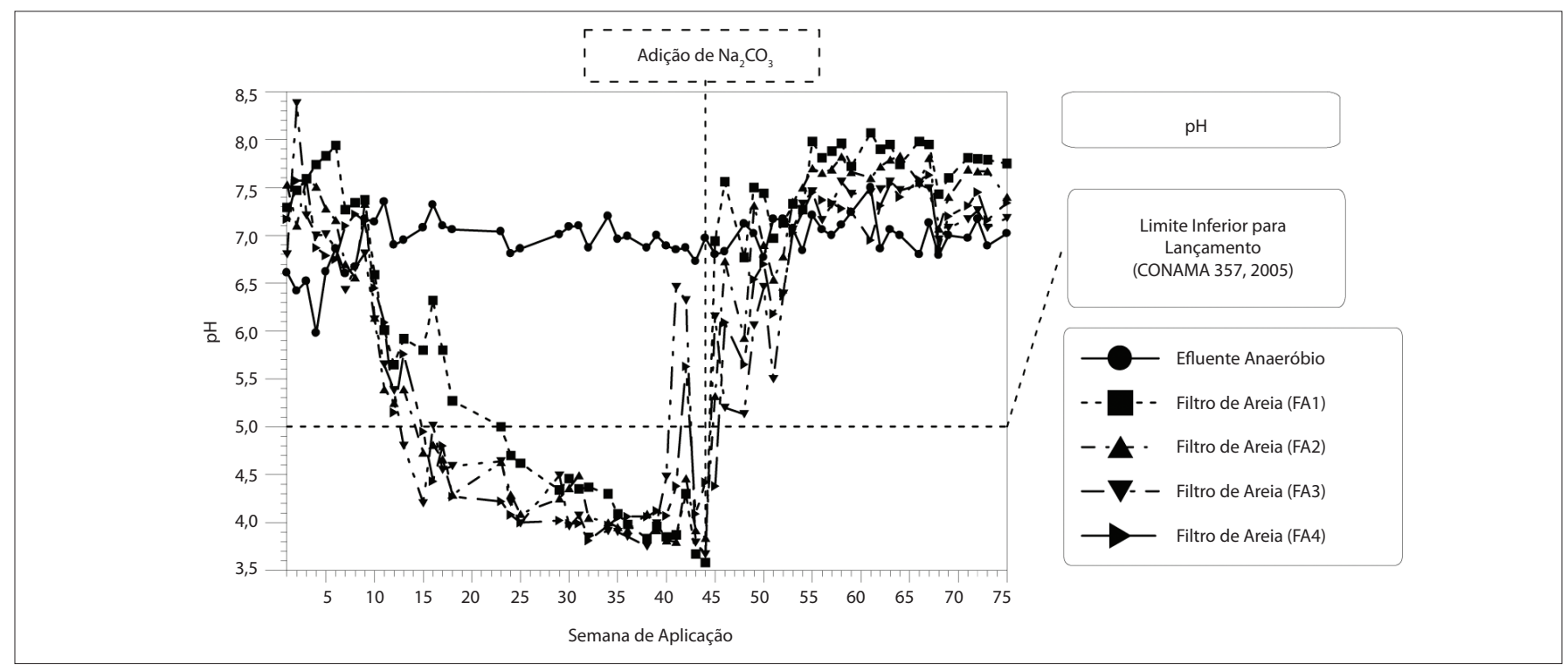

Figura 3 - pH do efluente dos filtros anaeróbios e filtros de areia.

Tabela 2 - Concentrações médias de nitrogênio total, nitrogênio total Kjeldahl, N-nitrito e N-nitrato presentes no efluente dos filtros de areia.

\begin{tabular}{|c|c|c|c|c|}
\hline Reator & $\mathrm{N}$-Total afluente $\left(\mathrm{mg} \cdot \mathrm{L}^{-1}\right)$ & $\mathrm{N}-\mathrm{NTK}\left(\mathrm{mg} \cdot \mathrm{L}^{-1}\right)$ & $\mathrm{N}-\mathrm{NO}_{2}{ }^{-}+\mathrm{N}-\mathrm{NO}_{3}{ }^{-}{ }^{-}\left(\mathrm{mg} \cdot \mathrm{L}^{-1}\right)$ & $\mathrm{N}$-Totalefluente $\left(\mathrm{mg} \cdot \mathrm{L}^{-1}\right)$ \\
\hline \multicolumn{5}{|c|}{ Filtros de areia (antes da adição de $\mathrm{Na}_{2} \mathrm{CO}_{3}$ ) } \\
\hline FA1 & \multirow{4}{*}{$41,9^{*}$} & $4,2^{\mathrm{a}}$ & $40,0^{a}$ & $44,2^{\mathrm{a}}$ \\
\hline FA2 & & $5,7^{\mathrm{ab}}$ & $31,3^{\mathrm{a}}$ & $37,0^{\mathrm{a}}$ \\
\hline FA3 & & $6,5^{\mathrm{bc}}$ & $29,7^{\mathrm{a}}$ & $36,2^{\mathrm{a}}$ \\
\hline FA4 & & $8,6^{c}$ & $26,3^{a}$ & $34.9^{a}$ \\
\hline
\end{tabular}

NTK: nitrogênio total Kjeldahl; FA1, FA2, FA3 e FA4: filtros 1, 2, 3 e 4, respectivamente.

Médias seguidas pela mesma letra minúscula na vertical não diferem entre si (Kruskal-Wallis $5 \%$ ).

${ }^{*} \mathrm{O} \mathrm{N}$-total afluente não apresentava diferença significativa com o $\mathrm{N}$-total efluente (Kruskal-Wallis $5 \%$ ). 
considerada como típica para efluentes domésticos, a qual encontra-se compreendida entre 200 e 500 mg.L.-1 (VON SPERLING, 2009). Os filtros anaeróbios propiciaram uma remoção média para todo o período da pesquisa de $68 \pm 9 \%$.

A legislação do estado de São Paulo (Decreto no 8.468/1976) estipula como valor limite para o lançamento de efluentes em corpos hídricos a DBO de 60 mg. $\mathrm{L}^{-1}$. Deste modo comprova-se que os filtros anaeróbios não possuíam a capacidade de cumprir tal norma legal, demandando um pós-tratamento, tal como afirmado por Chernicharo (2008). Neste ponto, ao adotarem-se os filtros de areia para cumprirem esta função, constata-se por meio da Tabela 5 uma remoção dos valores de DBO superior a 93\%, possibilitando que em todas as situações estudadas os efluentes destes reatores cumprissem tal legislação.

Não houve diferenças significativas (Kruskal-Wallis 5\%) entre os valores médios das DBO dos filtros de areia, demonstrando que nas frequências empregadas a eficiência dos leitos era similar para o tratamento. No entanto, os filtros que recebiam as maiores taxas de aplicação acabavam degradando uma maior carga de DBO diariamente (Tabela 5). Esta depuração da matéria orgânica, consumidora de oxigênio no processo metabólico, não acarretou em um comprometimento do efluente quanto à concentração de oxigênio dissolvido (OD) (Figura 5). Tal característica explicita a importância da intermitência da aplicação do afluente sobre a superfície dos filtros de areia, pois esta ação garantia condições aeróbias para as bactérias responsáveis pelo tratamento da matéria orgânica disposta.
Os resultados reforçam a robustez do tratamento proporcionado pelos reatores em estudo, pois as aplicações realizadas no filtro de areia que recebia a maior taxa diária de afluente $\left(200 \mathrm{~L} \mathrm{~m}^{-2} \cdot \mathrm{dia}^{-1}\right)$ deram-se entre as 9:00 e as 16:00 horas, ou seja, durante 7 horas em cada dia, sendo que as disposições estavam entremeadas por um período de descanso de 140 minutos. Caso seja feita uma extrapolação para o desempenho ao longo de todo um dia de funcionamento (24 horas) espera-se que seja possível dispor ao menos 10 aplicações diárias de 50 L.m ${ }^{-2}$, totalizando 500 L.m ${ }^{-2}$. dia ${ }^{-1}$, mantendo a mesma remoção de DBO obtida para as 7 horas realmente pesquisadas. Também não deve ser esquecido que a coleta dos efluentes dava-se na pior situação para o tratamento, ou seja, no primeiro momento em que havia um abrupto aumento na vazão de saída de efluente, caracterizado pelo menor contato entre o líquido e a cultura biológica.

A partir dessas informações conclui-se que quanto a este quesito a NBR 13969/1997 (ABNT, 1997), orientadora da construção de filtros de areia, é extremamente conservadora para a taxa limite de aplicação de efluente anaeróbio. Tal norma estipula o máximo de

Tabela 4 - Risco potencial de obstrução de gotejadores segundo a qualidade da água de irrigação (CAPRA; SCICOLONE, 1998).

\begin{tabular}{lccc} 
& \multicolumn{3}{c}{ Risco de obstrução } \\
\cline { 2 - 4 } Parâmetro & Baixo & Médio & Alto \\
\hline Sólidos em suspensão $\left(\mathrm{mg}^{\mathrm{L}} \mathrm{L}^{-1}\right)$ & $<50$ & 50 a 100 & $>100$ \\
$\mathrm{pH}$ & $<7,0$ & 7,0 a 8,0 & $>8,0$
\end{tabular}

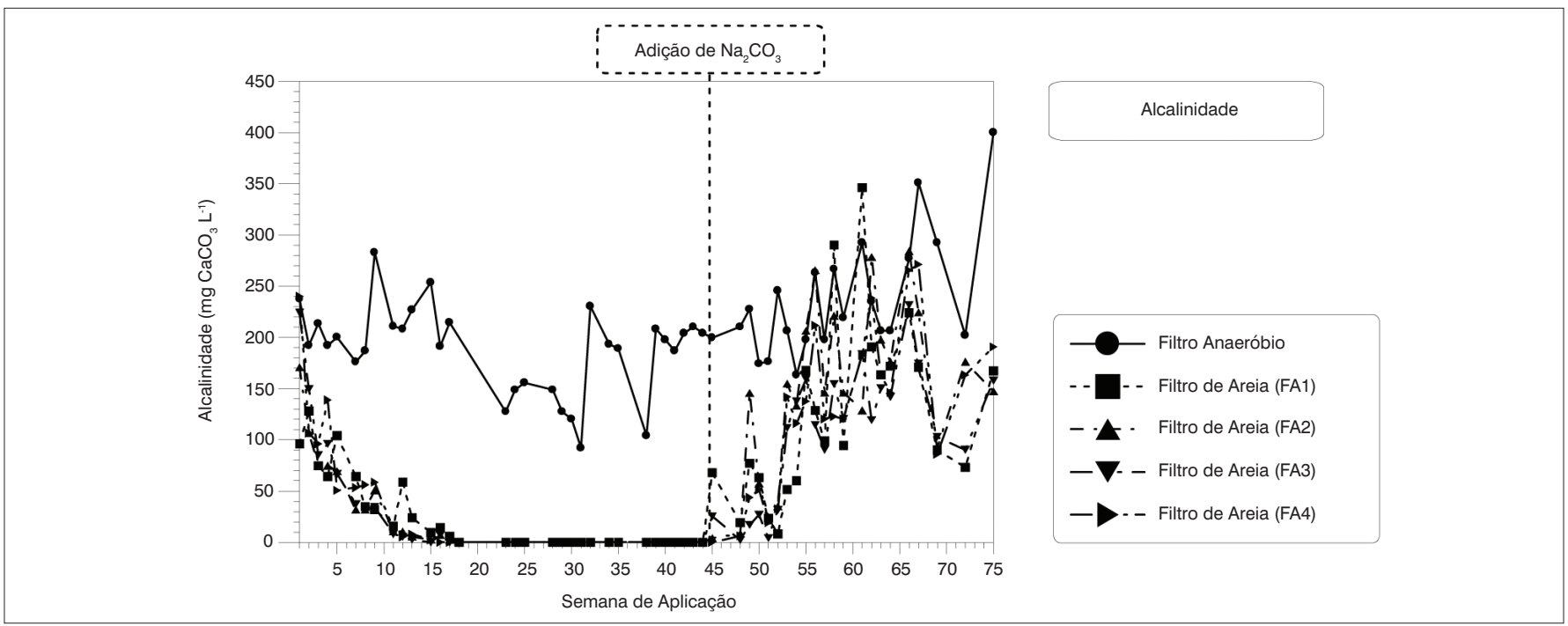

Figura 4 - Alcalinidade total dos efluentes dos filtros anaeróbios e filtros de areia.

Tabela 3 - Valores médios de turbidez e sólidos suspensos totais nos filtros de areia em relação ao efluente dos filtros anaeróbios.

\begin{tabular}{|c|c|c|c|c|}
\hline Reator & Turbidez (UT)* & Remoção (\%) & SST & Remoção \\
\hline Esgoto bruto & $79,8^{a}$ & - & $115^{a}$ & - \\
\hline Efluente anaeróbio & $57,9^{b}$ & $25,9^{a}$ & $66^{b}$ & $39^{a}$ \\
\hline FA1 & $8,1^{\mathrm{c}}$ & $86,8^{b}$ & $13^{c}$ & $74^{\mathrm{b}}$ \\
\hline FA2 & $12,2^{c}$ & $80,7^{b}$ & $22^{c}$ & $64^{b}$ \\
\hline FA3 & $6,3^{c}$ & $91,0^{c}$ & $10^{c}$ & $83^{b}$ \\
\hline FA4 & $7,8^{\mathrm{c}}$ & $88,8^{c}$ & $12^{c}$ & $81^{b}$ \\
\hline
\end{tabular}

SST: sólidos suspensos totais; FA1, FA2, FA3 e FA4: filtros 1, 2, 3 e 4, respectivamente.

Médias seguidas pela mesma letra minúscula na vertical não diferem entre si (Kruskal-Wallis $5 \%$ ). 
100 L.m ${ }^{-2}$.dia ${ }^{-1}$ para efluentes oriundos de tanques sépticos e em $200 \mathrm{~L} . \mathrm{m}^{-2}$. dia ${ }^{-1}$ quando proveniente de um tratamento aeróbio.

Conforme afirmado, por meio da Figura 5 percebe-se que as concentrações de OD nos efluentes dos filtros de areia, mesmo após um grande processo de remoção de matéria orgânica, foram superiores ao limite mínimo estabelecido para enquadramento como corpo de água de classe 2 (CONAMA, 2005), na grande maioria dos casos. Desta forma, quanto a este parâmetro, os efluentes poderiam ser empregados na irrigação de hortaliças, plantas frutíferas e de parques, além da aqüicultura.

Essas altas concentrações de OD demonstram a grande capacidade de aeração dos leitos operados intermitentemente, possivelmente ocasionado pelo tempo de descanso entre uma aplicação e outra. Assim, garantia-se a entrada de ar para o interior dos poros da areia, satisfazendo o metabolismo das bactérias aeróbias e também permitindo a diluição do oxigênio na massa líquida proveniente da disposição seguinte.

\section{Organismos indicadores de contaminação fecal}

A densidade média de coliformes totais e Escherichia coli existente no esgoto bruto foi respectivamente de $8,02 \times 10^{7} \pm 1,08 \times 10^{7}$ NMP $100 \mathrm{~mL}^{-1}$ e 4,16x10 $\pm 3,95 \times 10^{6} \mathrm{NMP} 100 \mathrm{~mL}^{-1}$, estando ambas dentro da faixa estipulada por Jordão e Pessoa (2005) como típica para águas residuárias domésticas, a qual para o primeiro conjunto de microrganismos varia entre $10^{6}$ e $10^{10} \mathrm{NMP} 100 \mathrm{~mL}^{-1}$ e para o segundo oscila de $10^{6}$ a $10^{9} \mathrm{NMP} 100 \mathrm{~mL}^{-1}$.

Após a passagem pelos filtros anaeróbios, as densidades aumentaram, chegando a $1,47 \times 10^{8} \pm 4,26 \times 10^{8} \mathrm{NMP} 100 \mathrm{~mL}^{-1}$ para os coliformes totais e $1,68 \times 10^{7} \pm 7,64 \times 10^{7} \mathrm{NMP} 100 \mathrm{~mL}^{-1}$ para E. coli, no entanto, não existia diferença significativa (Kruskal-Wallis $5 \%)$ em relação ao esgoto bruto. Assim, comprova-se a afirmação de Chernicharo (2008) de que os sistemas anaeróbios não apresentam uma remoção significativa quanto a estes parâmetros biológicos

Conforme se visualiza por meio da Tabela 6, os filtros de areia proporcionaram densidades menores, sendo que seus efluentes variaram nas proximidades de $10^{5} \mathrm{NMP} 100 \mathrm{~mL}^{-1}$ para coliformes totais e entre $10^{4} \mathrm{NMP} 100 \mathrm{~mL}^{-1}$ e $10^{5} \mathrm{NMP} 100 \mathrm{~mL}^{-1}$ para E. coli. Ambos os casos apontam para uma remoção próxima a 2,0 unidades logarítmicas, com os quatro filtros de areia proporcionaram médias sem diferença significativa (Kruskal-Wallis 5\%).
As médias e os valores pontuais para as densidades de E. coli dos filtros de areia estiveram acima do limite exigido pela legislação brasileira para o enquadramento em corpos hídricos de classes 2 e 3 (CONAMA, 2005), as quais possuem, respectivamente $1,0 \times 10^{3}$ e $2,5 \times 10^{3} \mathrm{NMP} 100 \mathrm{~mL}^{-1}$ como máximos. Em nenhum dos casos estudados foram encontrados ovos de nematoides (Ascaris, e Trichuris e Ancilóstomo).

Ao comparar os resultados obtidos com os valores microbiológicos sugeridos pela Organização Mundial da Saúde (OMS,2000) para uso de esgoto doméstico tratado, expostos na Tabela 7 , constata-se que os efluentes seriam enquadrados nas categorias B e C, viáveis para a irrigação por aspersão de cereais e culturas a serem industrializadas, silviculturas, árvores frutíferas e forrageiras para feno e silagem.

Torna-se importante explicitar que apesar do não atendimento em alguns casos da legislação brasileira (CONAMA, 2005) e da orientação da OMS (OMS, 2000) estas densidades poderiam ser facilmente reduzidas com o emprego de pequenas concentrações de um agente desinfetante. Neste caso, deve-se observar que a turbidez para estes efluentes foram muito baixas (Tabela 3), facilitando a ação do composto químico para a desinfecção do efluente.

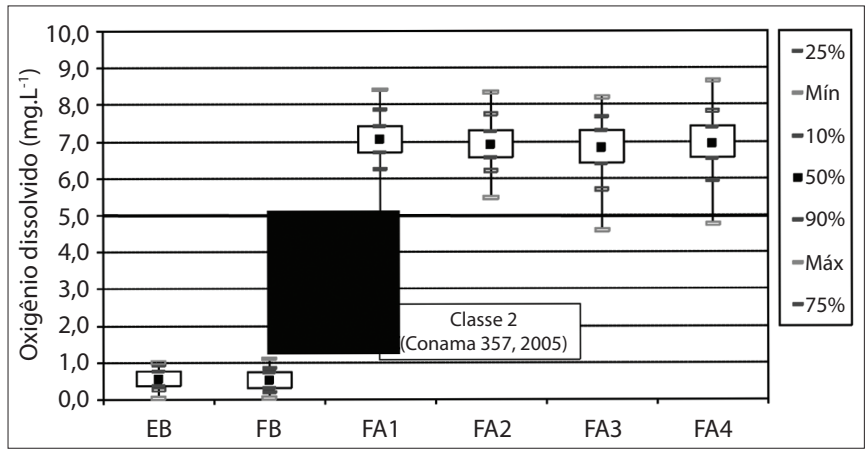

Figura 5 - Oxigênio dissolvido no esgoto bruto e no efluente dos filtros anaeróbios e filtros de areia e comparação com as classes de corpos de água (CONAMA, 2005).

Tabela 6 - Valores médios de densidade de coliformes totais e Escherichia coli nos efluentes dos filtros de areia.

$\begin{array}{lccc}\text { Reator } & \begin{array}{c}\mathrm{CT} \\ \left(\mathrm{NMP} 100 \mathrm{~mL}^{-1}\right)\end{array} & \begin{array}{c}\text { E. coli } \\ \left(\mathrm{NMP} 100 \mathrm{~mL}^{-1}\right)\end{array} & \begin{array}{c}\text { Remoção de } E \text {. coli } \\ (\%)\end{array} \\ \text { FA1 } & 1,09 \times 10^{5 a} & 3,09 \times 10^{4 a} & 98,99 \\ \text { FA2 } & 7,45 \times 10^{5 a} & 1,60 \times 10^{5 a} & 94,77 \\ \text { FA3 } & 5,22 \times 10^{5 a} & 1,08 \times 10^{5 a} & 95,76 \\ \text { FA4 } & 4,54 \times 10^{5 a} & 6,08 \times 10^{4 a} & 97,23\end{array}$

CT: coliformes totais; FA1, FA2, FA3 e FA4: filtros 1, 2, 3 e 4, respectivamente. Médias seguidas pela mesma letra minúscula na vertical não diferem entre si (Kruskal-Wallis 5\%).

Tabela 5 - Valores médios e carga de demanda bioquímica de oxigênio e de remoção nos filtros de areia em relação ao efluente dos filtros anaeróbios.

\begin{tabular}{|c|c|c|c|c|c|}
\hline Reator & DBO média (mg. L-1) & $\begin{array}{c}\text { Remoção em relação à } \\
\text { etapa anterior (\%) }\end{array}$ & Remoção global (\%)* & $\begin{array}{l}\text { Carga média efluente } \\
\qquad\left(\text { g. dia }{ }^{-1}\right)\end{array}$ & $\begin{array}{c}\text { Carga média depurada } \\
\qquad\left(\text { g.dia }^{-1}\right)\end{array}$ \\
\hline FA1 & $24^{a}$ & 85 & $94^{a}$ & 0,97 & 7,38 \\
\hline FA2 & $23^{a}$ & 84 & $94^{a}$ & 1,86 & 14,84 \\
\hline FA3 & $25^{a}$ & 83 & $94^{a}$ & 2,96 & 22,14 \\
\hline FA4 & $31^{\mathrm{a}}$ & 82 & $93^{a}$ & 4,87 & 28,53 \\
\hline
\end{tabular}

DBO: demanda bioquímica de oxigênio; FA1, FA2, FA3 e FA4: filtros 1, 2, 3 e 4, respectivamente. Médias seguidas pela mesma letra minúscula na vertical não diferem entre si (Kruskal-Wallis $5 \%$ ).

*Remoção em relação ao esgoto bruto. 
Tabela 7 - Valores microbiológicos para uso de esgoto doméstico tratado na aplicação em culturas (OMS, 2000).

\begin{tabular}{|c|c|c|c|c|}
\hline Categoria & Condições de reuso & Técnica de aplicação & $\begin{array}{l}\text { Ovos de nematoides }{ }^{1} \\
\text { (média aritmética por litro) }\end{array}$ & $\begin{array}{l}\text { Coliformes fecais } \\
\text { (NMP 100 } \mathrm{mL}^{-1} \text { ) }\end{array}$ \\
\hline A & $\begin{array}{l}\text { Irrigação de culturas que sejam comidas sem cozi- } \\
\text { mento, campos esportivos e parques públicos. }\end{array}$ & Qualquer & $\leq 0,1$ & $\leq 10^{3}$ \\
\hline \multirow{3}{*}{ B } & \multirow{3}{*}{$\begin{array}{l}\text { Cereais e culturas a serem industrializadas, silvi- } \\
\text { culturas, árvores frutíferas e forrageiras para feno } \\
\text { e silagem. }\end{array}$} & Aspersão & $\leq 1$ & $\leq 10^{5}$ \\
\hline & & Inundação e canal & $\leq 1$ & $\leq 10^{3}$ \\
\hline & & Qualquer & $\leq 0,1$ & $\leq 10^{3}$ \\
\hline C & $\begin{array}{l}\text { Aplicação localizada de culturas da categoria } B \text {, se } \\
\text { não ocorrer exposição de trabalhadores e público. }\end{array}$ & $\begin{array}{l}\text { Gotejamento e micro- } \\
\text { aspersão }\end{array}$ & Não aplicável & Não aplicável \\
\hline
\end{tabular}

${ }^{1}$ Ascaris e Trichuris e Ancilóstomo.

\section{Conclusões}

Os filtros de areia empregados no pós-tratamento de filtros anaeróbios proporcionaram a geração de efluentes com DBO abaixo do limite estipulado para o lançamento em corpos hídricos (Decreto Paulista nº 8.468/1976), sendo que os resultados apontaram para a possibilidade de disposição de taxas diárias superiores as sugeridas pela NBR 13969/1997 (ABNT, 1997), a qual orienta os aspectos construtivos para esta forma de tratamento.
Quanto à possibilidade de reúso, ao comparar os resultados obtidos com os valores microbiológicos sugeridos pela OMS (OMS, 2000) para uso de esgoto doméstico tratado, constata-se que o efluente produzido seria viável para a irrigação de cereais e culturas a serem industrializadas, silviculturas, árvores frutíferas e forrageiras para feno e silagem. Confrontando com os valores propostos por Capra e Scicolone (1998), no tocante a concentração de sólidos suspensos, o efluente teria risco baixo de obstrução dos gotejadores.

\section{Referências}

AMERICAN PUBLIC HEALTH ASSOCIATION; AMERICAN WATER WORKS ASSOCIATION; WATER ENVIRONMENT FEDERATION (APHA; AWWA; WEF). (2005) Standard methods for the examination of water and wastewater. 19th ed. New York: American Public Health Association.

ASSOCIAÇÃO BRASILEIRA DE NORMAS TÉCNICAS. (1995) NBR 6502: rochas e solos: análise granulométrica conjunta. São Paulo.

ASSOCIAÇÃO BRASILEIRA DE NORMAS TÉCNICAS. (1997) NBR 13969: tanques sépticos: unidades de tratamento complementar e disposição final dos efluentes líquidos. Projeto, construção e operação. São Paulo.

AUSLAND, G., STEVIK, T.K., HANSSEN, J.F., KOHLER, J.C., JENSSEN, P.D. (2002) Intermittent filtration of wastewater - removal of fecal coliforms and fecal streptococci. Water Research, v. 36, n. 14, p. 3507-3516.

CAMARGO, S.A.R.; NOUR, E.A.A. (2001) Bamboo as an anaerobic medium: effect of filter column height. Water Science and Technology, v. 44, n. 4, p. $63-70$

CAPRA, A.; SCICOLONE, B. (1998) Water quality and distribution uniformity in drip/trickle irrigation systems. Journal of Agricultural Engineering Research, v. 70, n. 4, p. 355-365.

CHERNICHARO, C. (2008) Reatores anaeróbios. Belo Horizonte: UFMG

CONSELHO ESTADUAL DE POLÍTICA AMBIENTAL (COPAM). (1986) Deliberação Normativa $n^{\circ} 10$ de 16 de dezembro de 1986.Estabelece normas e padrões para qualidade das águas, lançamento de efluentes nas coleções de águas, e dá outras providências. Diário do Executivo de Minas Gerais de 10 de janeiro de 1987. Disponível em:<http://www.siam.mg.gov. br/sla/download.pdf?idNorma=91 > . Acesso em: 28 nov. 2012

CONSELHO NACIONAL DE MEIO AMBIENTE (CONAMA). (2005) Resolução n 357 de 17 de março de 2005. Dispõe sobre a classificação dos corpos de água e diretrizes ambientais para o seu enquadramento, bem como estabelece as condições e padrões de lançamento de efluentes, e dá outras providências. Diário Oficial da União, n. 53, de 18 de março de 2005, p. 58-63. Disponível em: <http://www.mma.gov.br/ port/conama/processos/61AA3835/LivroConama.pdf > . Acesso em: 28 nov. 2012.

COUTO, L.C.C.; FIGUEIREDO, R.F. (1992) Filtro anaeróbio com bambu para tratamento de esgotos domésticos. In: Congreso Interamericano de Ingenieria Sanitaria y Ambiental. AIDIS, La Habana, Cuba, p. 329-340.

INSTITUTO BRASILEIRO DE GEOGRAFIA E ESTATÍSTICA (IBGE). (2008) Pesquisa Nacional de Saneamento Básico. Rio de Janeiro: IBGE. Disponível em: <http://www.ibge.gov.br/home/estatistica/populacao/ condicaodevida/pnsb2008/PNSB_2008.pdf>. Acesso em: 28 nov. 2012.

JORDÃO, E.P.; PESSOA, C.A. (2005) Tratamento de esgotos domésticos. $3 a$ ed. Rio de Janeiro: ABES.

METCALF; EDDY. (2003) Wastewater engineering, treatment, disposal and reuse.4th ed. NewYork: McGraw-Hill, International Editions.

ORGANIZAÇÃO MUNDIAL DA SAÚDE (OMS). (2000) Guidelines for the microbiological quality of treated wastewater used in agriculture: recommendations for revising WHO guidelines. Bulletin of World Health Organization, v. 78, n. 9. Genebra.

TONETTI, A.L.; CORAUCCI FILHO, B.; BERTONCINI, E.I.; OLIVEIRA R.A.; STEFANUTTI, R. (2010) Avaliação de um sistema simplificado de tratamento de esgotos visando a utilização em áreas rurais. Revista Brasileira de Engenharia Agrícola e Ambiental, v. 14, n. 2, p. 227-234

TONETTI, A.L.; CORAUCCI FILHO, B.; GUIMARÃES, J.R.; CRUZ, L.M.O.; NAKAMURA, M.S. (2011) Avaliação da partida e operação de filtros anaeróbios tendo bambu como material de recheio. Revista Engenharia Sanitária e Ambiental, v. 16, n. 1, p. 11-16.

VON SPERLING, M. (2009) Introdução a qualidade das águas e ao tratamento de esgotos. 2a ed. Belo Horizonte: UFMG. p. 452. 